Vascul ar Endot hel i al Grouth Fact or - bound St ent s: Appl i cat i on of I n- si t u Capt ure Technol ogy of Ci rcul at ing Endothel i al Progeni tor Cel I s i n Por ci ne Cor onary Model

\begin{tabular}{|c|c|}
\hline 著者 & 高畠 周 \\
\hline 著者別表示 & Takabat ake Shu \\
\hline $\begin{array}{l}\text { j our nal or } \\
\text { publ i cat i on titl e }\end{array}$ & 博士論文本文Ful I \\
\hline 学位授与番号 & 13301甲第4007号 \\
\hline 学位名 & 博士 (医学) \\
\hline 学位授与年月日 & $2014-03-22$ \\
\hline URL & ht t p: //hdl . handl e. net /2297/40481 \\
\hline
\end{tabular}




\title{
Vascular Endothelial Growth Factor-Bound Stents: Application of In Situ Capture Technology of Circulating Endothelial Progenitor Cells in Porcine Coronary Model
}

\author{
SHU TAKABATAKE, M.D., ${ }^{1}$ KENSHI HAYASHI, M.D., ${ }^{1}$ CHIAKI NAKANISHI, M.D., ${ }^{1}$ \\ HIROYUKI HAO, M.D., ${ }^{2}$ KENJI SAKATA, M.D., ${ }^{1}$ MASA-AKI KAWASHIRI, M.D., ${ }^{1}$ \\ TAKEHISA MATSUDA, PH.D., ${ }^{3}$ and MASAKAZU YAMAGISHI, M.D. ${ }^{1}$ \\ From the ${ }^{1}$ Division of Cardiovascular Medicine, Kanazawa University Graduate School of Medicine, Kanazawa, Japan; ${ }^{2}$ Department of \\ Surgical Pathology, Hyogo College of Medicine, Nishinomiya, Japan; and ${ }^{3}$ Genome Biotechnology Laboratory, Kanazawa Institute of \\ Technology, Hakusan, Ishikawa, Japan
}

\begin{abstract}
Objectives: We evaluated the in vivo performance of a newly devised vascular endothelial growth factor (VEGF)bound stent in a porcine coronary model.

Background: An anti-CD34 antibody-bound stent, which captures endothelial progenitor cells (EPCs) to accelerate tissue formation, did not reduce intimal hyperplasia. By targeting the VEGF receptor, which is expressed on endothelial-lineage cells, we developed VEGF-bound stents that may enable selective capture of EPCs followed by rapid endothelialization.

Methods: Metallic stents were first coated with poly-(ethylene-co-vinyl alcohol), and then chemically bound with either VEGF or anti-CD34 antibody. These stents were placed in porcine coronary arteries for up to 14 days. Stent surface was evaluated by immunohistochemistry and by scanning electron microscope (SEM).

Results: After 2-day stenting with VEGF-bound stents, small populations of KDR (VEGF receptor-2)-positive cells adhered to the stent struts. After 7-and 14-day stenting, struts were fully covered with newly regenerated tissue. SEM images showed that the uniform tissue formed on struts was morphologically similar to native endothelium and was continuously connected with adjacent native endothelium. On the other hand, for the anti-CD34 antibody-bound stents, stent struts were rapidly covered by newly generated tissue that consisted of multicellular aggregates.

Conclusions: Compared with anti-CD34 antibody-bound stents, VEGF-bound stents provide highly selective capture of EPCs, followed by rapid formation of intact endothelium tissue at an early period of stenting. These results suggest that VEGF-bound stents could represent a promising therapeutic option for cardiovascular stenting, although further long-term follow-up experiment with double-blinded fashion is needed prior to clinical application. (J Interven Cardiol 2014;27:63-72)
\end{abstract}

\section{Introduction}

Drug-eluting stents (DESs) have shown dramatic efficacy in reducing neointimal hyperplasia through inhibition of smooth-muscle cell proliferation at an early period of stenting. ${ }^{1-3}$ However, major drawbacks

Grant sponsor: The Ministry of Education, Culture, Sports, Science and Technology of Japan.

Address for reprints: Masakazu Yamagishi, Division of Cardiovascular Medicine, Kanazawa University Graduate School of Medicine, 13-1 Takara-Machi, Kanazawa 920-8641, Japan. Fax: +81-76234-4210; e-mail: myamagi@med.kanazawa-u.ac.jp of DES include delayed formation of a functional monolayer of endothelial cells (ECs) over the stent, abrupt thrombus formation, and restenosis due to in-stent neointimal tissue hyperplasia in later periods of stenting. ${ }^{4-8}$ One logical solution to avoiding these drawbacks is to develop a system that promotes rapid regeneration of a functional endothelium on the stent. Endothelial progenitor cells (EPCs) circulating in arterial blood flow can adhere and differentiate into mature ECs at sites of injured vessels, thereby enhancing reendothelialization and restoring endothelial function. ${ }^{9-11}$ Therefore, rapid and selective capture of EPCs on the stent struts could avoid thrombus 
formation and reduce neointimal hyperplasia. EPCs constitute a minor fraction of CD34-expressing cells. A recently developed EPC-caputuring stent which surface was coated with anti-CD34 antibody accelerated tissue formation and failed to reduce the following intimal hyperplasia. ${ }^{12}$ Although no report has described the cell types on such stents, various cell types of CD34-positive mononuclear cells other than EPCs may adhere. ${ }^{13,14}$ This could adversely affect the integrity of the tissue architecture as well as the function of any ECs present. Therefore, it is unclear whether CD34 is the best marker for cells with capturing, differentiating, and endothelializing potential. Cell surface receptors exclusively expressed on endothelial-lineage cells include vascular endothelial growth factor (VEGF) receptors and Tie molecules. Our previous study of mononuclear cell culture on surfaces coated with various types of proteins, including antibodies to these receptors and VEGF, showed that VEGF-bound surfaces exhibit high adhesion, proliferation, and differentiation potentials. ${ }^{15,16}$ Based on these previous results, we devised a new VEGF-bound stent aiming at highly selective capture of EPCs and rapid formation of intact endothelium. ${ }^{15}$ In the current study, we report on the in vivo performance of VEGF-bound stents in an early period of stenting (up to 2 weeks after coronary implantation) in a porcine model, focusing especially on whether EPCs were captured from local arterial blood flow by VEGF-bound stents, and to what extent endothelialization was achieved. We also compared these outcomes with those noted in anti-CD34 antibody-bound stents. Both VEGF- and anti-CD34 antibody-bound stents were prepared in-house according to the same protocol.

\section{Methods}

Stents. Stents were made of cobalt-chromium (kindly supplied by NIPRO Corp., Shiga, Japan) and had the following dimensions: length, $8 \mathrm{~mm}$; diameter, $2.75-3.0 \mathrm{~mm}$ in the deployed state; wall thickness, $75 \mu \mathrm{m}$. Stents were coated with poly(ethylene-co-vinyl alcohol) (68 mole \% of vinyl alcohol, $5 \mu \mathrm{m}$ thick) using an ultrasonic atomizing spray-coating apparatus (Sono-Tek, Milton, NY, USA), followed by activation of surface hydroxyl groups by N,N-carbodiimidazole in acetonitrile. Subsequently, the coated stents were subjected to protein binding using either recombinant
VEGF $_{165}$ (referred to as VEGF, purchased from PeproTech, Rocky Hill, NJ, USA) or anti-porcine CD34 antibody (R\&D Systems, Inc., Minneapolis, $\mathrm{MN}, \mathrm{USA}$ ) in phosphate-buffered saline (PBS) at room temperature. The coated surfaces were smooth without cracking and delamination upon deployment. The fully saturated density of VEGF on the surface was confirmed at the protein-binding step using the relationship between fluorescence intensity and fluorescently labeled protein concentration. The detailed preparation and characterization procedures are described in our previous article. ${ }^{15}$

Experimental Procedures. Animal experiments were performed in compliance with the NIH Guide for Care and Use of Laboratory Animals and Guidelines of Kanazawa University School of Medicine. Domestic female swine ( $\mathrm{N}=26$, average weight $25 \pm 5 \mathrm{~kg}$ ) were used for implantation studies. Before each procedure, animals were given $200 \mathrm{mg}$ aspirin (Bayer, Land Nordrhein-Westfalen, Germany) and $300 \mathrm{mg}$ clopidogrel (Sanofi Aventis, Gouda, The Netherlands) as loading doses, or $200 \mathrm{mg}$ aspirin and $75 \mathrm{mg}$ clopidogrel daily until the end of the experiment. Each animal received an intramuscular injection of ketamine hydrochloride $(20 \mathrm{mg} / \mathrm{kg})$ and was maintained under general anesthesia with $2 \%$ halothane oxygen.

ECG, heart rate, and arterial blood pressure were continuously monitored using a polygraph recording system (OptiPlex755, Nihon-Kohden, Tokyo, Japan) throughout the entire procedure. A 6F-guiding catheter was advanced to the coronary artery through the left carotid artery. A bolus of heparin (5,000 IU) was administered intravenously, and an additional 2,000 IU was injected every hour. We performed coronary angiography using a cineangiography system (ARCADIS Avantic, SIEMENS, Malvern, PA, USA). Under guidance by intravascular ultrasound imaging (GALAXY2 IVUS Imaging System, Boston Scientific, Natick, MA, USA), VEGF-bound or anti-CD34 antibody-bound stents were implanted into the proximal to mid portion of coronary arteries, with an intended balloon-artery ratio of 1.1:1. The intravascular ultrasound observation was performed only for confirmation of complete stent a position at the time of stent implantation. In the present study, the swine were randomly implanted with same or different types of stents. Animals were sacrificed 2 days (harvested stents: 12 VEGF-bound stents, 7 anti-CD34 antibodybound stents), 7 days (6 VEGF-bound stents, 5 antiCD34 antibody-bound stents), or 14 days (13 VEGF- 


\section{VASCULAR ENDOTHELIAL GROWTH FACTOR-BOUND STENTS}

bound stents, 15 anti-CD34 antibody-bound stents) after implantation. In the present study, we did not perform further long-term observation because the main purpose was to verify rapid capture of EPC at an early period of stenting and accelerated endothelialization.

Tissue Preparation. The coronary arteries, dissected with a minimum of surrounding tissue, were preserved for histological $(\mathrm{N}=10)$ and immunohistochemical $(\mathrm{N}=17)$ examinations. Specimens were fixed for 24 hours with $20 \%$ formalin and embedded in paraffin. For scanning electron microscope (SEM) $(\mathrm{N}=31)$, samples were fixed for 2 hours with $2.0 \%(\mathrm{v} /$ v) glutaraldehyde in PBS and subsequently treated with a series of dehydration steps using graded aqueous solutions of $50 \%, 60 \%, 70 \%, 80 \%, 90 \%, 99 \%$, and $100 \%$ ethanol for 10 minutes at each step. Next, samples were treated twice with 2-methyl-2-propanol. The samples were then frozen at $-20^{\circ} \mathrm{C}$ for 1 hour, freeze-dried for 2 hours in an ES-2030 freeze dryer (Hitachi High-Technologies, Tokyo, Japan), and sputter-coated with osmium (VIII) oxide.

Morphometric and Histological Analysis. Paraffin-embedded tissue was deparaffinized and then stained immunohistochemically. VEGF receptor-positive cells were evaluated by staining with an antibody against KDR (07-716, Merck Millipore, Darmstadt, Germany) to detect endothelial-lineage cells. These specimens were rinsed with PBS and labeled with Alexa Fluor 488-conjugated goat anti-rabbit IgG antibody (A-11029, Invitrogen, Carlsbad, CA, USA). Nuclei were stained with Hoechst (33342 Dojin Laboratories, Kumamoto, Japan) at a dilution ratio of 1:1,000. Immunofluorescence images were obtained using a BIOREVO fluorescence microscope system (BZ-9000, Keyence, Osaka, Japan). After plastination in Technovit 9100 methacrylate-based resin (HeraeusKulzer, Werheim, Germany), 5-6- $\mu \mathrm{m}$ cross-sections were acquired from each stent using a Leica RM2145 rotary microtome (Leica Microsystems $\mathrm{GmbH}$, Wetzlar, Germany). The specimens were stretched and placed on prepared microscopic slides, and then stained with hematoxylin-eosin (H-E). Neointimal thickness was measured along a line perpendicular to the neointima and top of the strut and between the strut (total of 24 points were averaged). For immunohistochemical staining of neointima, Ki67 (ab833, Abcam, Cambridge, UK) was used as a proliferation marker; proliferation activity was defined quantitatively as the proportion of Ki67-positive cells in the neointimal area.
Digital microscope images were recorded on a VHX500 (Keyence). SEM images were recorded on a HITACHI SEM-EDX (Hitachi-Technologies) at an acceleration voltage of $10 \mathrm{kV}$.

Statistics. All data are expressed as mean \pm SD. An unpaired t-test was used for comparison between the groups with VEGF-bound stents and anti-CD34 antibody-bound stents. A P-value of $<0.05$ was considered statistically significant.

\section{Results}

A total of 58 stents were implanted in the coronary arteries of 26 swine: 22 VEGF-bound stents for 11 swine and 19 anti-CD34 antibody-bound stents for 9 swine. In the remaining 6 swine, both VEGF- $(n=9)$ and antiCD34 antibody- $(n=8)$ bound stents were implanted. Thus, there were a few mixed types of stents deployment. Under these conditions, expanded stent diameters determined by intravascular ultrasound were $2.66 \pm$ $0.14 \mathrm{~mm}$ in VEGF-bound stents and $2.76 \pm 0.12 \mathrm{~mm}$ (NS) in anti-CD34 antibody-bound stents. All 58 stents remained patent during the implantation period (up to 2 weeks) without evidence of stent thrombosis. Actually, there were no problems during experimental procedures. In the following sections, we describe representative observations made on implanted stents.

VEGF-Bound Stents. After 2 days of stenting digital microscopy revealed that most of the strut surface area was naked, whereas a smaller area was covered by a thin layer of tissue (Fig. 1A). SEM images revealed a small number of cells adherent to struts (Fig. 1B-D). Most of these adherent cells, which were not attached to native endothelium, immunostained with anti-KDR antibody (Fig. 2), indicating that circulating EPCs were captured on stent struts in the early period of stenting. At 7 days, strut surfaces were completely covered by a thin layer of tissue, as revealed by both digital microscopy and SEM (Fig. 3A and B). Higher magnification SEM images showed that the surfaces were fully covered by cells (Fig. 3C and D). At 14 days, struts were completely embedded in relatively thick tissue (Fig. 4A). SEM images revealed that tissue formed on struts was composed of endothelial-like cells with cobblestone morphology and was continuously connected to adjacent native endothelium (Fig. 4B and C). The tissue generated on strut surfaces was approximately $20 \mu \mathrm{m}$ thick in this example (Fig. 4D). Under these conditions, there still existed 


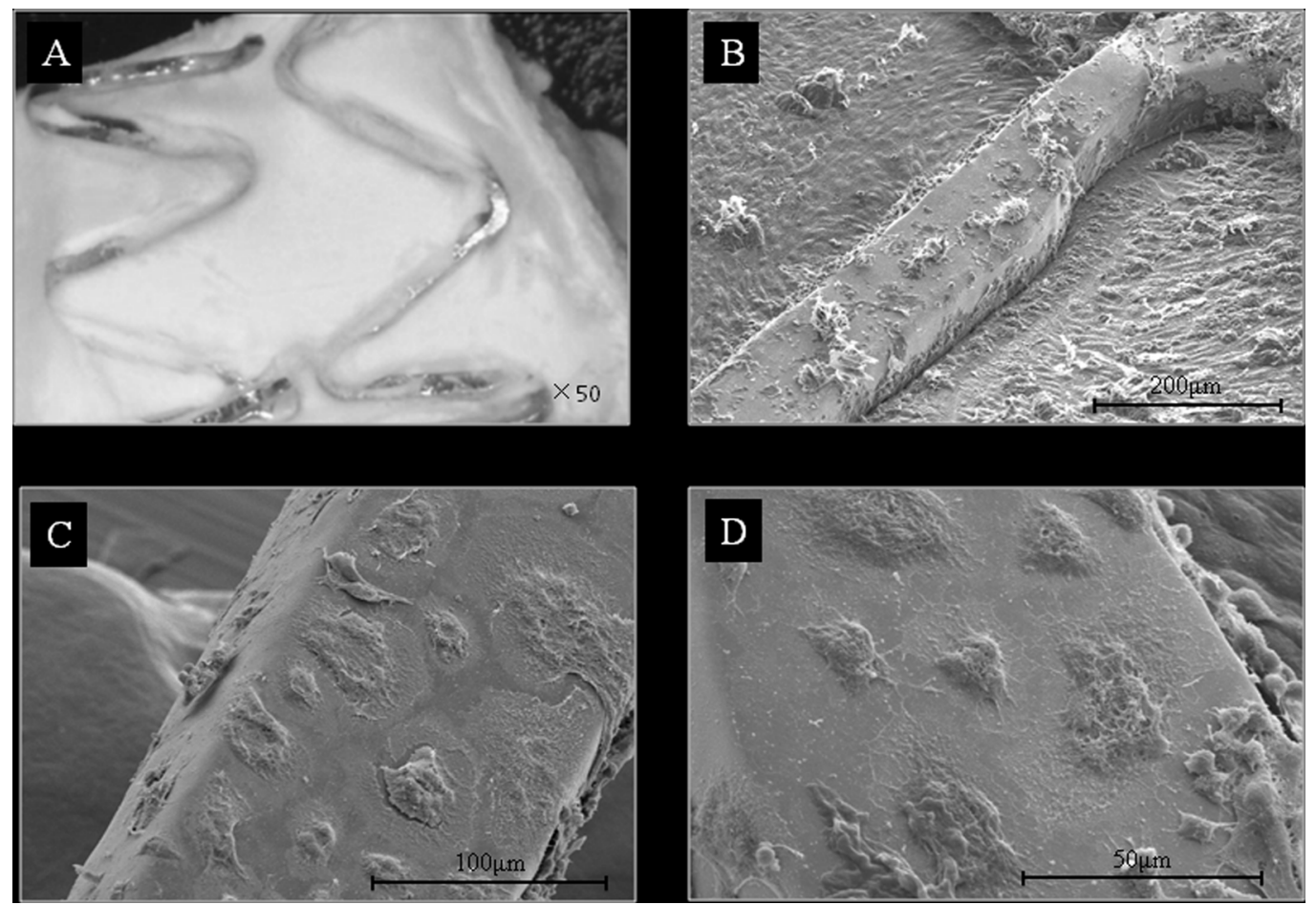

Figure 1. VEGF-bound stent after 2-day stenting. (A) Digital microscopic image showing naked and thin layer regions of the stent. (B-D) SEM images showing adherent cells captured from the bloodstream.

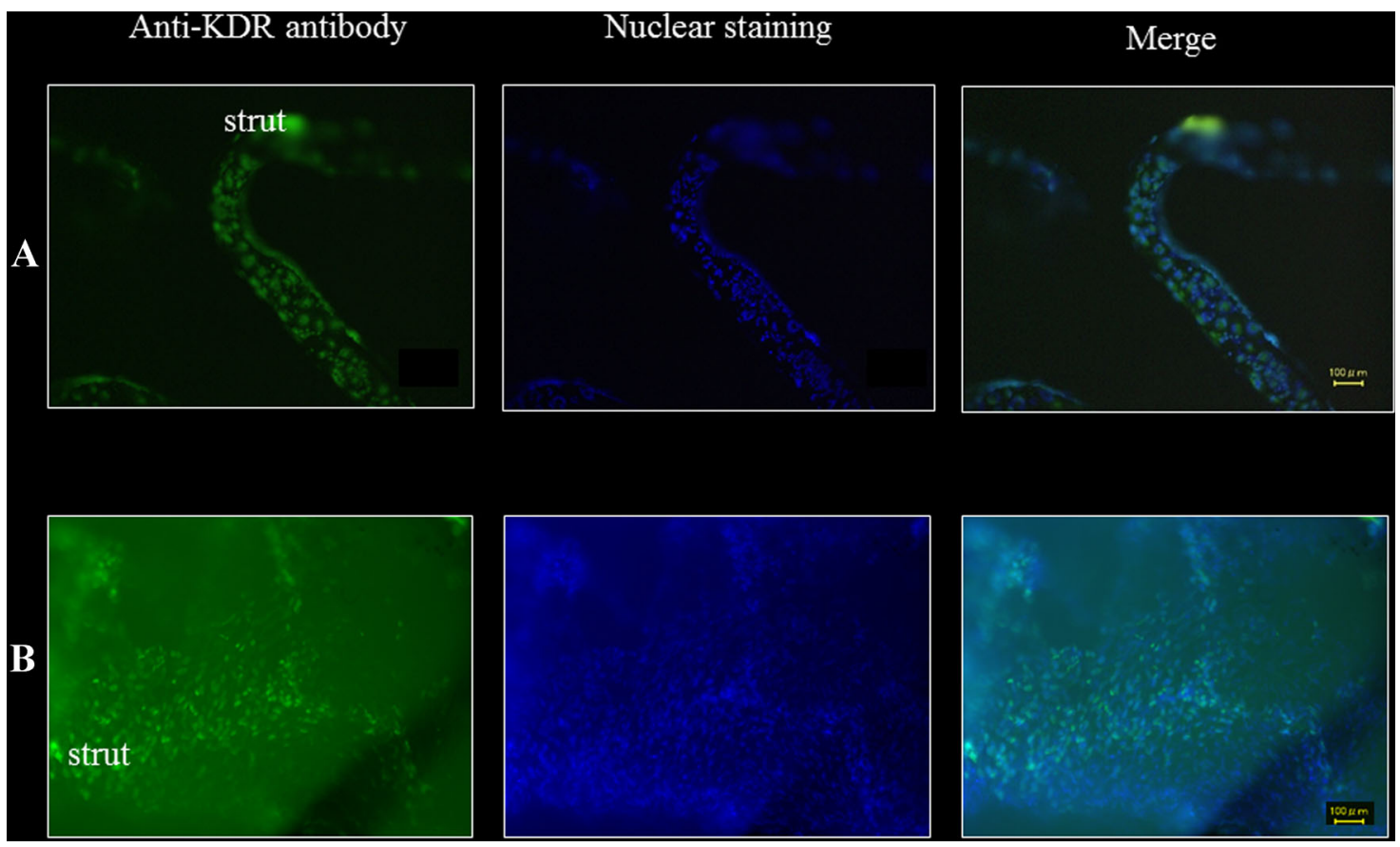

Figure 2. Immunofluorescence staining of adhered cells captured on the stent strut after 2-day (A) and 14-day (B) stenting. Left: anti-KDR antibody staining; center: nuclear staining (Hoechst, blue); right: merge. 


\section{VASCULAR ENDOTHELIAL GROWTH FACTOR-BOUND STENTS}

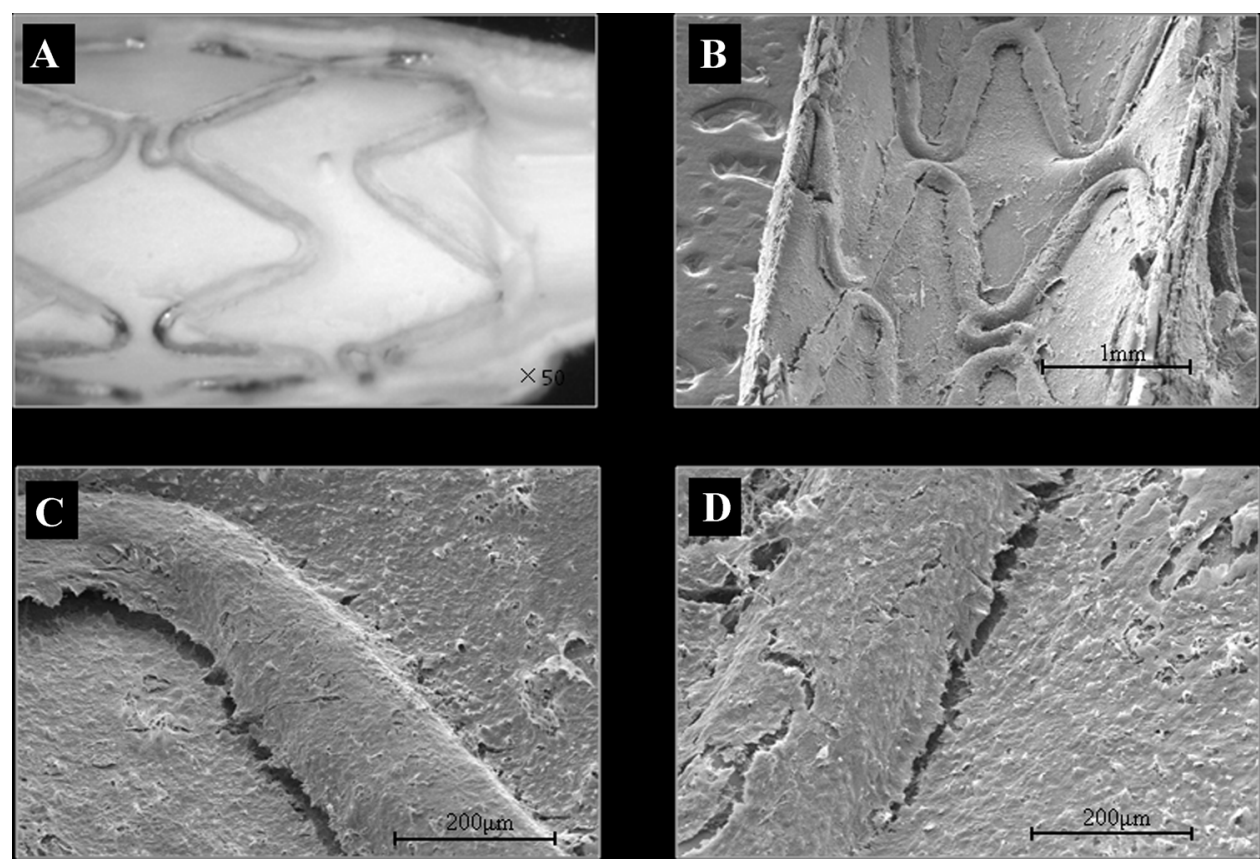

Figure 3. VEGF-bound stent after 7-day stenting. (A) Digital microscopic image showing the strut surface almost completely covered with a thin layer of tissue. (B-D) SEM images showing complete coverage by endothelial-like cells.

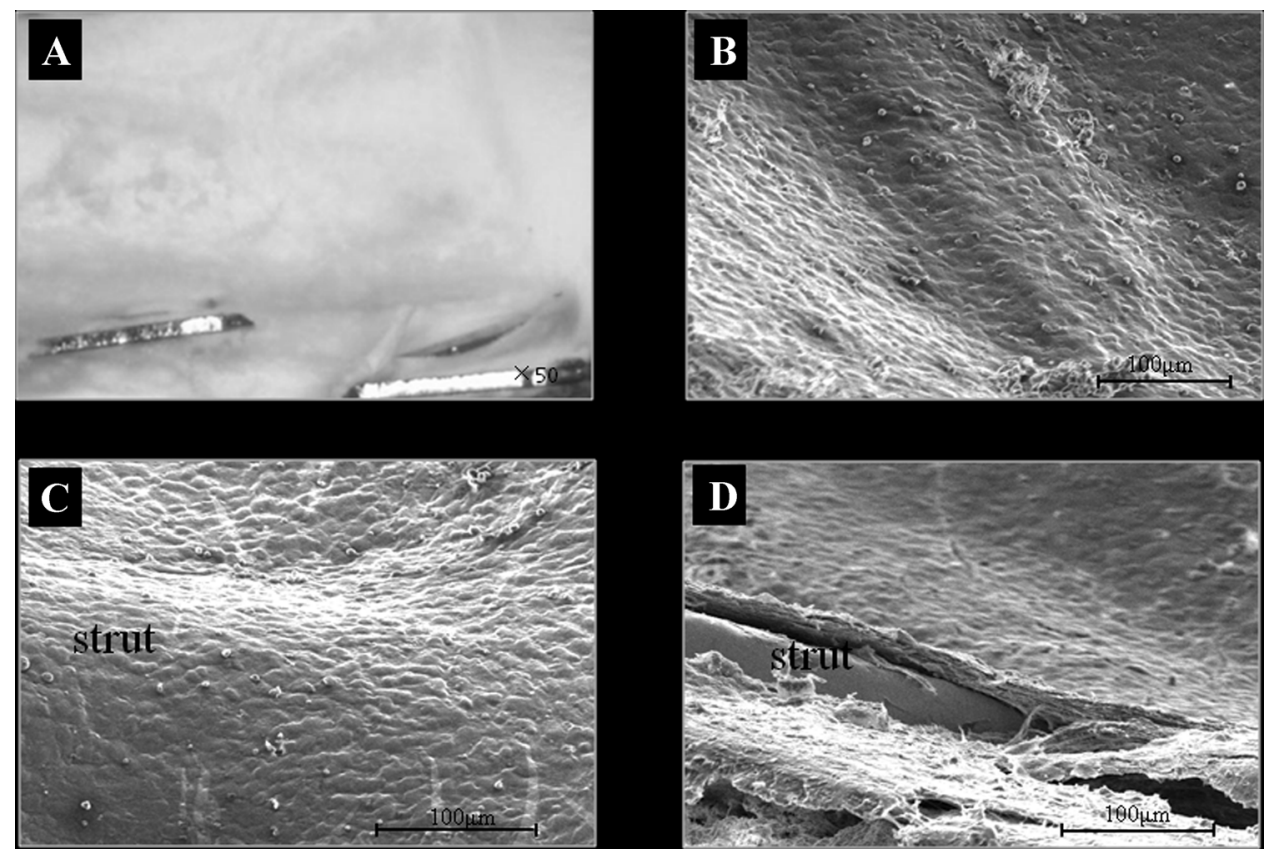

Figure 4. VEGF-bound stent after 14-day stenting. (A) Digital microscopic image showing that stents are completely embedded in a newly generated tissue. (B and C) SEM images showing uniform endothelial tissue with cobblestone morphology. (D) SEM image of cross-sectional specimen. Note that intimal tissue on stent strut is approximately $20 \mu \mathrm{m}$ thick. 
KDR-positive cells located within stent struts as well as adjacent vascular tissue (Fig. 2).

\section{Anti-CD34 Antibody-Bound Stents. After} 2 days of stenting the surfaces of anti-CD34 antibody-bound stents were completely covered by regenerated tissue (Fig. 5A), which was composed of multicellular aggregates (Fig. 5B). At 7 days, the stents were completely embedded in newly generated tissue (Fig. 5C). SEM images revealed the presence of some endothelial-like cells, but for the most part multicellular aggregates were observed (Fig. 5D). At 14 days, the stent was embedded in thick tissue (Fig. 6A). SEM images revealed that the tissue was of mixed types, composed of both multicellular-disorganized tissue (Fig. 6B and C) and endothelium-like tissue (Fig. 6D).

Neointimal Tissue: VEGF-Bound Stents Versus Anti-CD34 Antibody-Bound Stents. Interestingly, proliferative cells detected by Ki67 (Fig. 7A) revealed that the proportion of proliferating to total cells in the neointimal tissue was much higher for the anti-CD34 antibody-bound stent $(47.9 \pm 3.6 \%)$ than for the VEGF-bound stent $(29.2 \pm 10.3 \%)$ (Fig. 7B). Indeed, the average neointimal thickness of VEGF-bound stent was $67.9 \pm 30.5 \mu \mathrm{m}$ (Fig. $8 \mathrm{~A}$ ) and was thinner than that of the anti-CD34 antibody-bound stent with $79.8 \pm$ $28.7 \mu \mathrm{m}$ (Fig. 8B).

\section{Discussion}

The present study demonstrates that the newly manufactured VEGF-bound stents can selectively capture KDR-positive cells in the early phase after deployment in porcine coronary arteries. Furthermore, relatively smooth neointimal proliferation is observed with less cellular activity than is noted in anti-CD34 antibody-bound stents. These results suggest that VEGF-bound stents can contribute to vital endothelial architecture and may facilitate repair of diseased coronary arteries. The DES has been widely used for the treatment of coronary artery disease to reduce both restenosis rates and target lesion revascularization. However, recent clinical studies have shown that antiproliferative drugs eluted from such stents often interfere with the natural vascular healing process. ${ }^{17}$ To minimize or circumvent such events, recent efforts have focused on capturing circulating EPCs onto stent struts by biospecifically targeting EPCs with the cell surface marker CD34, and EPCs have been detected in the multicellular CD34-positive fraction of mononuclear cells. In animal experiments, an anti-CD34 antibody-bound stent appeared to accelerate tissue formation, but did not reduce neointimal thickness compared with a noncoated bare metal stent. ${ }^{12}$ In

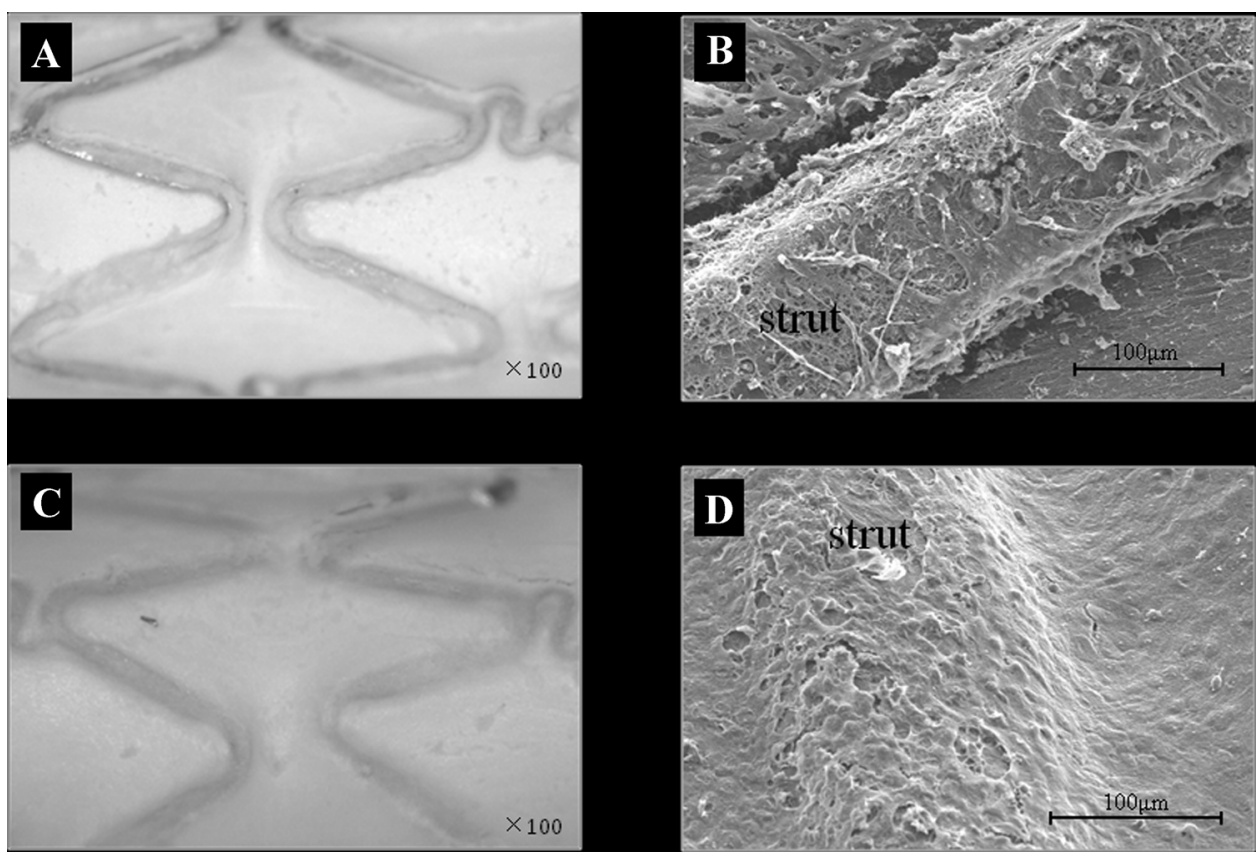

Figure 5. Anti-CD34 antibody-bound stents after 2-day (A and B) and 7-day stenting (C and D). (A and C) Digital microscopic images showing a surface of strut covered by newly generated tissue. (B and D) SEM images showing disorganized tissue on struts. 


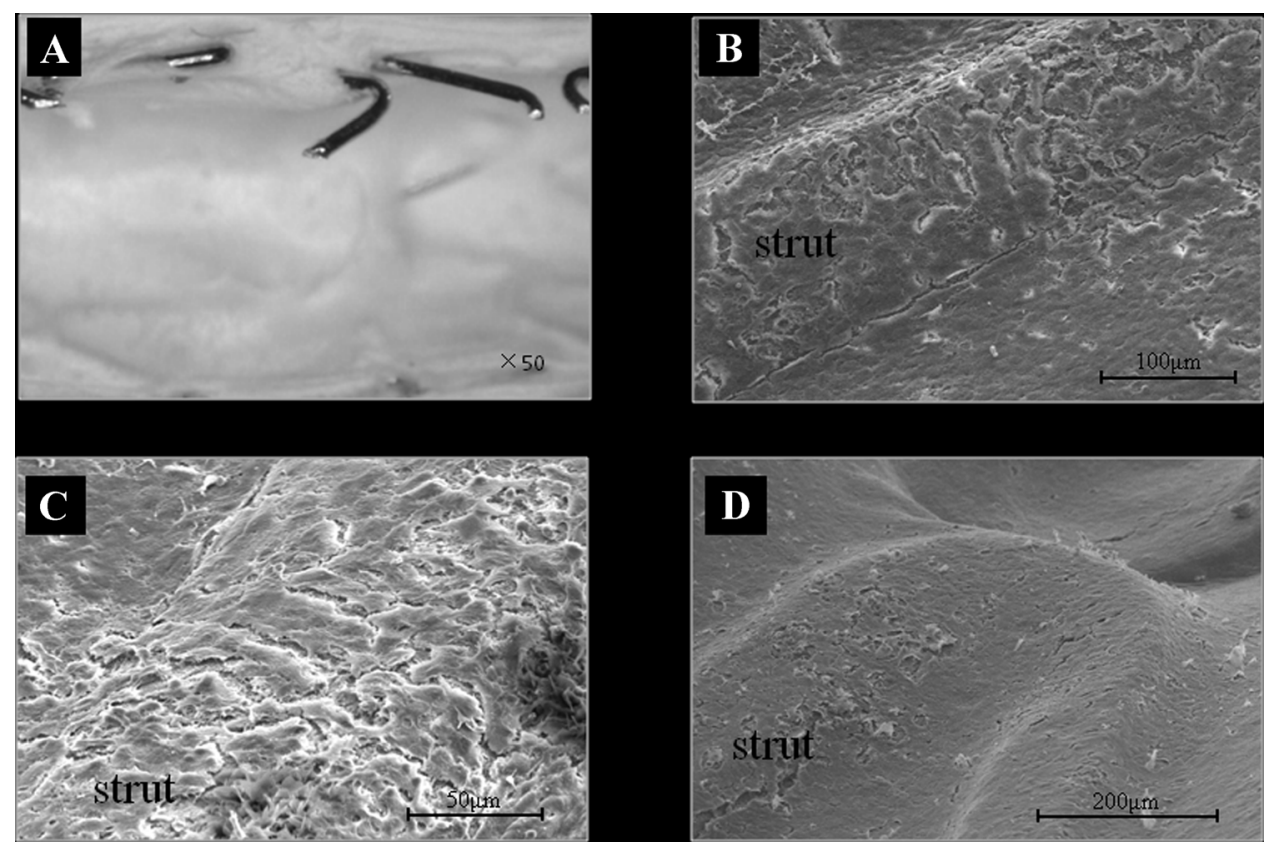

Figure 6. Anti-CD34 antibody-bound stents after 14-day stenting. (A) Digital microscopic image showing stent struts embedded in thick tissue. (B and C) SEM images showing tissue composed of multicellular aggregates. (D) SEM image showing endothelium-like tissue.

A
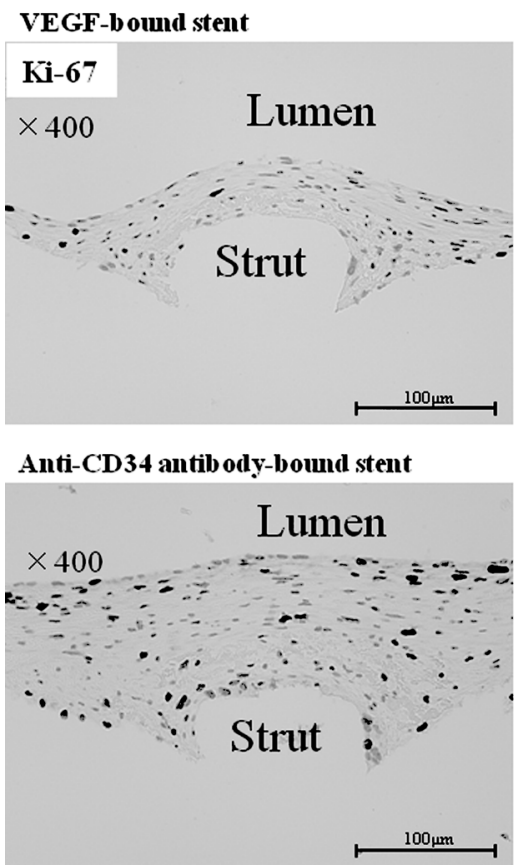

B

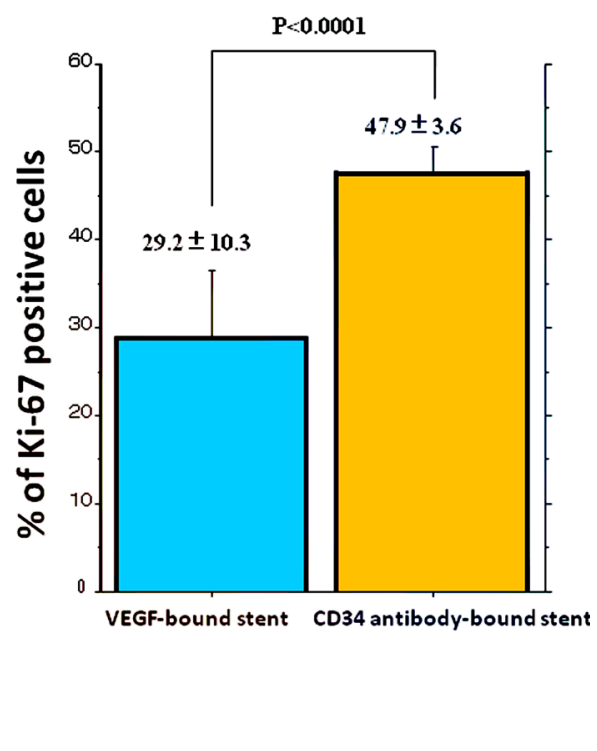

Figure 7. Ki67-positive cells in neointimal tissue on VEGF-bound and anti-CD34 antibody-bound stent after 14-day stenting. Note that the proportion of proliferative cells, assessed by Ki67 staining (A), is significantly higher in the neointimal tissue of the anti-CD34 antibody-bound stents than that of the VEGF-bound stents (B). 


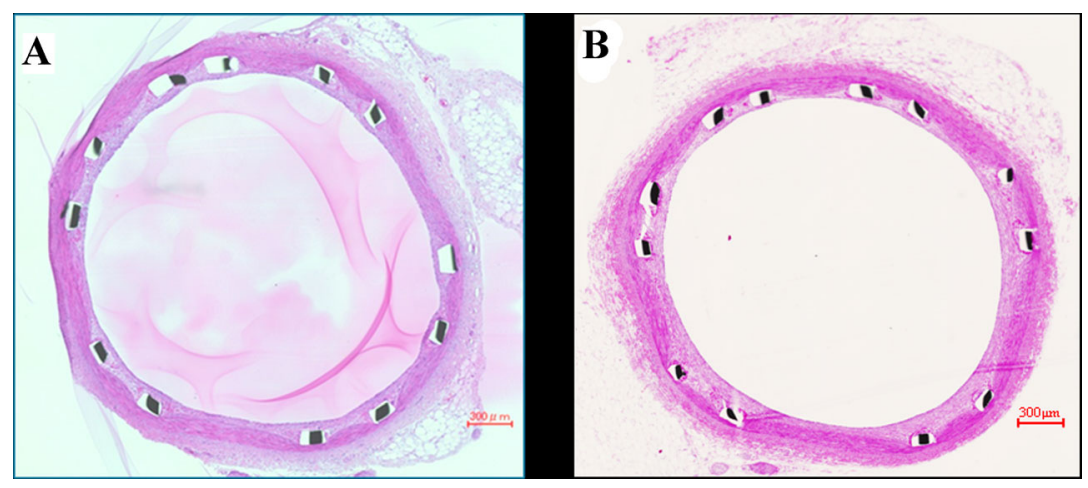

Figure 8. Microscopic images of cross-sectional specimens of coronary arteries with (A) VEGF-bound and (B) anti-CD34 antibody-bound stents harvested after 14-day stenting (hematoxylin-eosin staining).

clinical trials, these stents have not been therapeutically effective, due to the high rate of target-lesion failure and stent thrombosis. ${ }^{18,19}$ In the present study, we attempted to apply VEGF instead of anti-CD34 antibody to facilitate formation of endothelium for early repair of injured vessel walls. An ideal scenario for vital formation of endothelium on stent struts is highly selective in situ capture of EPCs from arterial blood flow and subsequent full endothelialization during the early period after implantation. To achieve this goal, we conducted a series of preliminary studies ${ }^{15,16,20,21}$ prior to verification of "proof-ofconcept" in an animal model as was done in the present study. Based on these data, the main theme of this study was to verify that EPCs are captured from arterial blood flow, and to determine the degree to which endothelialization is promoted on a VEGFbound platform. There are 2 possible pathways leading to endothelialization on stent struts: capture of EPCs circulating in arterial blood flow and migration of ECs from adjacent native tissue. Although we cannot exclude a contribution of the latter pathway to endothelialization, immunohistochemistry demonstrates direct rapid capture of KDR-positive cells on stent struts, which were not contacted by native endothelium in the bloodstream. Importantly, such EPC capture occurs within 2 days after stenting. This is also supported by ex vivo studies of ours ${ }^{21}$ and others $^{22,23}$ providing important proof in concept that EPC adhesion occurs and high adhesion retention holds under physiological levels of hydrodynamic shear stress. Subsequently, endothelialization is completed within 1-2 weeks after stenting proceeds (Figs. 3 and 4).
On the other hand, tissue generated on anti-CD34 antibody-bound stents exhibited quite disorganized tissue architecture, composed of a mixture of multicellular aggregates and endothelium-like tissue (Figs. 5 and 6). Interestingly, the proportion of proliferating cells in neointimal tissue was approximately 1.5 times higher for anti-CD34 antibody-bound stents than for VEGF-bound stents (Fig. 8) associated with somewhat increased neointimal thickness in comparison with that in VEGF-bound stents after 14-day stenting. Although we did not randomize stents for implantation, the present results can provide the superiority of VEGF to anti-CD34 antibody-bound stents for early endothelialization. The study with implantation of 2 types of stents in 1 swine will give more credible results than those in the present study in terms of endothelial coverage and intimal hyperplasia. Also, long-term implantation may further differentiate the neointimal tissue architectures between these 2 types of stents.

Our previous study showed that the anti-thrombogenic potential of human EPCs is almost half that of human ECs, in terms of production of prostacyclin, tissue plasminogen activator, and nitric oxide synthetase. $^{24}$ Furthermore, ex vivo EPC-seeded smalldiameter grafts exhibited thrombus-free performances in a canine carotid artery model, ${ }^{25}$ and ex vivo EPCseeded stents performed well in vitro. ${ }^{24}$ These observations suggest that cooperative action of a prolonged matricine effect induced by VEGF bound to the stent surface and the mechanotransduction effect caused by continuous shear stress loading from arterial blood flow eventually accelerate differentiation and endothelialization in the arterial bloodstream. Recently, an anti-VE-cadherin antibody-bound stent was shown 


\section{VASCULAR ENDOTHELIAL GROWTH FACTOR-BOUND STENTS}

to capture endothelial-lineage cells more selectively than an anti-CD34 antibody-bound stent, resulting in faster and higher quality endothelium formation. ${ }^{26,27}$ VE-cadherin is expressed on cell surfaces of ECs at a later stage of endothelialization, and VE-cadherin molecules engage in homophilic interactions at adherens junctions in adjacent ECs. Although mechanistic aspects of EPC capture at the cellular level may differ, both types of stents might contribute to vital endothelial architecture, and hopefully may provide better choices for repair of diseased coronary arteries. In the present study, we used healthy swine basically without coronary atherosclerosis. Therefore, it may be premature to transfer the present results into clinical settings such as coronary artery disease. A study with atherosclerotic swine models ${ }^{28}$ may resolve this issue which is important for clinical application.

\section{Conclusions}

The present study demonstrates that in comparison to anti-CD34 antibody-bound stents, VEGF-bound stents can achieve highly selective capture of EPCs followed by accelerated natural endothelial tissue formation. Rapid, high-quality, and intact endothelium tissue formation represents a promising therapeutic option for cardiovascular stenting, although the further long-term follow-up experiment is needed prior to clinical application.

\section{References}

1. Uchiyama K, Ino H, Hayashi K, et al. Impact of severe coronary disease associated or not associated with diabetes mellitus on outcome of interventional treatment using stents: Results from HERZ (Heart Research Group of Kanazawa) analyses. J Int Med Res 2011;39:549-557.

2. Morice MC, Serruys PW, Sousa JE, et al. A randomized comparison of a sirolimus-eluting stent with a standard stent for coronary revascularization. N Engl J Med 2002;346:1773-1780.

3. Babapulle MN, Joseph L, Belisle P, et al. A hierarchical Bayesian meta-analysis of randomised clinical trials of drug-eluting stents. Lancet 2004;364:583-591.

4. Carter AJ, Aggarwal M, Kopia GAL. Long-term effects of polymer-based, slow-release, sirolimus-eluting stents in a porcine coronary model. Cardiovasc Res 2004;263:617-624.

5. Bavry AA, Kumbhani DJ, Helton TJ, et al. Late thrombosis of drug-eluting stents: A meta-analysis of randomized clinical trials. Am J Med 2006;119:1056-1061.

6. Windecker S, Meier B. Late coronary stent thrombosis. Circulation 2007;116:1952-1965.

7. Tada H, Kawashiri MA, Sakata K, et al. Impact of out-stent plaque volume on in-stent intimal hyperplasia: Results from serial volumetric analysis with high-gain intravascular ultrasound. Int J Cardiol 2012;158:235-239.
8. Kawashiri MA, Sakata K, Uchiyama K, et al. Impact of lesion morphology and associated procedures for left main coronary stenting on angiographic outcome after intervention: Sub-analysis of Heart Research Group of Kanazawa, HERZ, Study. Cardiovasc Interv Ther (in press). doi: 10.1007/s12928-013-0222-8

9. Werner N, Junk S, Laufs U, et al. Intravenous transfusion of endothelial progenitor cells reduces neointima formation after vascular injury. Circ Res 2003;93:17-24.

10. Kong D, Melo LG, Mangi AA. Enhanced inhibition of neointimal hyperplasia by genetically engineered endothelial progenitor cells. Circulation 2004;109:1769-1775.

11. Urbich C, Dimmeler S. Endothelial progenitor cells; characterization and role in vascular biology. Circ Res 2004;95:343353.

12. van Beusekom HM, Ertas G, Sorop O, et al. The genous endothelial progenitor cell capture stent accelerates stent reendothelialization but does not affect intimal hyperplasia in porcine coronary arteries. Catheter Cardiovasc Interv 2012;79: 231-242.

13. Simper D, Stalboerger PG, Panetta CJ, et al. Smooth muscle progenitor cells in human blood. Circulation 2002;106:1199_ 1204.

14. Inoue T, Sata M, Hikichi Y, et al. Mobilization of CD34-positive bone marrow-derived cells after coronary stent implantation: Impact on restenosis. Circulation 2007;115:553-561.

15. Matsuda T, Kuwana M, Aomizu T, et al. Surface design for in situ capture of endothelial progenitor cells: VEGF-bound surface architecture and behaviors of cultured mononuclear cells. J Biomed Mater Res B Appl Biomater 2013;101:50-60.

16. Miyazu K, Kawahara D, Ohtake H, et al. Luminal surface design of electrospun small-diameter graft aiming at in situ capture of endothelial progenitor cell. J Biomed Mater Res B Appl Biomater 2010;94:53-63.

17. Joner M, Finn AV, Farb A. Pathology of drug-eluting stents in humans: Delayed healing and late thrombotic risk. J Am Coll Cardiol 2006;48:193-199.

18. Bystron M, Cervinka P, Spacek R, et al. Randomized comparison of endothelial progenitor cells capture stent versus cobaltchromium stent for treatment of ST-elevation myocardial infarction. Six-month clinical, angiographic, and IVUS followup. Catheter Cardiovasc Interv 2010;76:627-639.

19. Beijk MA, Klomp M, Verouden NJ, et al. Genous endothelial progenitor cell capturing stent vs. the Taxus Liberte stent in patients with de novo coronary lesions with a high-risk of coronary restenosis: A randomized, single-centre, pilot study. Eur Heart J 2010;31:1055-1065.

20. Suzuki Y, Yamamoto K, Ando J, et al. Arterial shear stress augments the differentiation of endothelial progenitor cells adhered to VEGF-bound surfaces. Biochem Biophys Res Commun 2012;423:91-97.

21. Kawahara D, Matsuda T. Hydrodynamic shear-stress-dependent retention of endothelial and endothelial progenitor cells adhered to vascular endothelial growth factor-fixed surfaces. J Biomed Mater Res B Appl Biomater 2012;100:12181228.

22. Angelos MG, Brown MA, Satterwhite LL, et al. Dynamic adhesion of umbilical cord blood endothelial progenitor cells under laminar shear stress. Biophys J 2010;99:354-360.

23. Brandon D, Markway BS, Owen JT, et al. Capture of flowing endothelial cells using surface-immobilized anti-kinase insert domain receptor antibody. Tissue Eng Part C 2008;14: 21-30.

24. Shirota T, Yasui H, Shimokawa H, et al. Fabrication of endothelial progenitor cell (EPC)-seeded intravascular stent devices and in vitro endothelialization on hybrid vascular tissue. Biomaterials 2003;24:2295-2303. 
TAKABATAKE, ET AL.

25. He H, Shirota T, Yasui $H$, et al. Canine endothelial progenitor cell-lined hybrid vascular graft with nonthrombogenic potential. J Thorac Cardiovasc Surg 2003;126:455-464.

26. Lim WH, Seo WW, Choe W, et al. Stent coated with antibody against vascular endothelial-cadherin captures endothelial progenitor cells, accelerates re-endothelialization, and reduces neointimal formation. Arterioscler Thromb Vasc Biol 2011;31: 2798-2805.
27. Lee JM, Choe W, Kim BK, et al. Comparison of endothelialization and neointimal formation with stents coated with antibodies against CD34 and vascular endothelial-cadherin. Biomaterials 2012;33:8917-8927.

28. Hamamdzic D, Wilensky RL. Porcine models of accelerated coronary atherosclerosis: Role of diabetes mellitus and hypercholesterolemia. J Diabetes Res 2013;2013:761415. 